Veterinarian's dilemma

a study of how Danish small animal practitioners handle financially limited clients

Kondrup, Sara Vincentzen; Anhøj, K. P.; Rødsgaard-Rosenbeck, C.; Lund, Thomas Bøker; Nissen, Merete Holst; Sandøe, Peter

Published in:

Veterinary Record

DOI:

10.1136/vr.103725

Publication date:

2016

Document version

Peer reviewed version

Citation for published version (APA):

Kondrup, S. V., Anhøj, K. P., Rødsgaard-Rosenbeck, C., Lund, T. B., Nissen, M. H., \& Sandøe, P. (2016).

Veterinarian's dilemma: a study of how Danish small animal practitioners handle financially limited clients.

Veterinary Record, 179, [596]. https://doi.org/10.1136/vr.103725 


\title{
The Veterinarian's dilemma: A study of how Danish small animal practitioners handle financially limited clients ${ }^{1}$
}

Sara V. Kondrup ${ }^{1}$, MSc; Kiea P. Anhøj ${ }^{2}$, DVM; Cecilie Rødsgaard-Rosenbeck ${ }^{2}$, DVM; Thomas B. Lund ${ }^{1}$, PhD; Merete H. Nissen ${ }^{3}$, DVM; Peter Sandøe*1 \& 2 , D.Phil.(Oxon.)

* Corresponding author, pes@sund.ku.dk

${ }^{1}$ Department of Food and Resource Economics, University of Copenhagen, Rolighedsvej 25, 1958 Frederiksberg C., Copenhagen, Denmark

${ }^{2}$ Department of Large Animal Sciences, University of Copenhagen, Grønnegårdsvej 8, 1870 Frederiksberg C., Copenhagen, Denmark

${ }^{3}$ University Hospital for Companion Animals, Department of Veterinary Clinical and Animal Sciences, University of Copenhagen, Dyrlægevej 16, 1870 Frederiksberg C., Copenhagen, Denmark

\begin{abstract}
This study examined the extent to which Danish veterinary practices encounter financially limited clients, and how different factors relating to the animal, the client and the veterinarian affect decisions to provide treatment for these clients. 300 small animal practices were invited to participate in an online survey. 195 participated, giving a response rate of $65 \%$. The results show that Danish small animal veterinary practices encounter clients with limited finances regularly: $33.80 \%$ of them 3-4 times, $24.60 \%$ 5-10 times, and 19.50\% 1-2 times a month. Only around $9 \%$ reported having a written practice policy on handling financially limited clients. Factors affecting decisions to treat include the severity and type of the animal's condition, the medical care needed, and the client's expressed emotions. The propensity to treat is significantly higher in female veterinarians and in situations involving unborn animals. The overall conclusion is that small animal veterinary practices often provide treatment to clients who are not able to pay - far beyond what is legally required. This can be considered a major economic and psychological challenge for the practicing veterinarians.
\end{abstract}

\section{Introduction}

Presented with a client who cannot afford to pay for treatment in full, the small animal veterinarian is likely to feel a range of obligations and responsibilities - to the client, to the animal under her or his care, to colleagues and the practice, and to the veterinary profession as a whole. These responsibilities often clash, leaving the veterinarian with an ethical dilemma

\footnotetext{
${ }^{1}$ The reference of the printed version is:

Kondrup, S. V., Anhøj, K. P., Rødsgaard-Rosenbeck, C., Lund, T. B., Nissen, M. H., \& Sandøe, P. (2016). Veterinarian's dilemma: a study of how Danish small animal practitioners handle financially limited clients. Veterinary Record, 179, [596]. Doi: 10.1136/vr.103725

The definitive version is available at

http://veterinaryrecord.bmj.com/content/179/23/596
} 
(Tannenbaum 1993; Graaf 2005; Morgan 2007; Batchelor and McKeegan 2012). What makes dilemmas of this sort special, as compared with other dilemmas faced by veterinarians, is that they involve companion animals, which are increasingly viewed as family members (Greenebaum 2004; Hens 2008; Power 2008), resulting in high expectations of veterinary care. As Tannenbaum points out, close human attachments to animals situate medical care as something, to which people and their animals are entitled (Tannenbaum 1995). So the moral stakes are high when small animal veterinarians are making decisions about how to handle financially limited clients.

This paper presents the results of a study of how Danish small animal practices handle financially limited clients. Financially limited clients are here defined as clients who express an inability to pay prior to treatment of their animal. Situations where a client seeks to avoid paying after treatment has been provided are not considered. In Denmark there are few options of financial support available to clients with limited means, as opposed to, for example, the United Kingdom (UK). In the UK there are several national and local organisations that provide support and funding or veterinary help to animal owners in financial difficulties, e.g. the Blue Cross Animal Hospitals, the Royal Society for the Prevention of Cruelty to Animals (RSPCA), the Dogs Trust, and the People's Dispensary for Sick Animals (PDSA). The largest animal welfare organisation in Denmark, the Danish Animal Welfare Society, provides veterinary treatment to sick or injured wild animals and stray cats, but if veterinary assistance is given to an owned animal, the bill reverts to the owner. So, in Denmark, there are fewer opportunities for getting financial support in situations where clients cannot pay than in the UK, but even in the UK resources for this kind of support is limited, and in the UK as in Denmark, veterinarians face difficulties when clients are not able to pay.

By law, a veterinarian operating in Denmark is required to provide the necessary first aid to seriously injured animals, those with painful diseases or other animals where immediate care is deemed necessary (Retsinformation 2004). However, in such a situation, euthanasia is considered a legally accepted way of dealing with the problem (B. Broberg, personal communication). In the UK, veterinary surgeons face the same obligations as part of their registration with the Royal College of Veterinary Surgeons (RCVS) (Royal College of Veterinary Surgeons n.d.). Thus when a client requests veterinary care for an ill or injured animal, but is unable to pay, the veterinarian is potentially torn between, on the one hand, client expectations and obligations to the animal, which speak in favour of effective therapeutic treatment, and on the other hand, responsibilities to her or his veterinary business, which favour less costly minimal treatment.

To the authors' knowledge, little research into how many financially limited clients visit small animal veterinarians, and how veterinarians experience and handle such situations, has been reported. In a small-scale survey in the UK of first-opinion veterinary surgeons, Batchelor and McKeegan (2012) found that veterinary surgeons regularly face ethical dilemmas, and that they find these dilemmas stressful. 'Financial limitations on treatment' was reported as the most common problem, ahead of 'convenience euthanasia of a healthy animal' and 'the client 
wishing to continue treatment despite compromised animal welfare/quality of life'. The last of these scenarios was rated as the most stressful situation, but the other two scenarios were also rated as highly stressful. No effect of years in practice was found in relation to the stress ratings. In two of the scenarios (healthy animal euthanasia and clients wishing to continue treatment) female veterinarians were found to experience more stress than their male colleagues. Although Batchelor and McKeegan did not find a significant association between the degrees of stress experienced by female veterinarians and number of situations they had encountered involving financial limitations on treatment, their study indicates that female veterinarians are more sensitive to difficult situations than their male colleagues. The authors suggest that one of the factors in experienced stress is, in general, the lack of guidance on how to make difficult ethical decisions: $78 \%$ of the respondents in the study felt that they were not given enough (or in many cases any) ethics tuition during their training.

Although partly a question of veterinary ethics, handling financially limited clients also falls within the scope of veterinary business management, which has also been shown to be lacking in veterinary medical education (Walsh and others 2002; Kogan 2005; Henry and Treanor 2012), and given low priority among veterinary practitioners. This is apparent from several studies that found low levels of adoption of some widely accepted best-practice businessmodels among veterinarians (Brown and Silverman 1999; Cron 2000; Volk and others 2005; Kogan 2015). Veterinary ethics and business management may appear to be opposing elements of the veterinarian's professional competence, but clearly both play a direct role in situations involving financially limited clients. In such situations ethical engagement with the animal and the client may well clash with the financial imperatives of the clinic. The clash probably explains why monetary issues have been shown to be a challenge to veterinarians when they are communicating with clients (Milani 2003; Coe and others 2007; Coe and others 2008) and when they are calculating appropriate charges for their services (Routly 2002; Gilling and Parkinson 2009; Bachynsky 2013). It may also help to explain why payment is a relatively rare topic of discussion between veterinarians and clients (Coe 2009).

When clients state an inability to pay for the necessary treatment the veterinarian has several options: to offer instalment agreements, reduce fees, do pro bono work, or shape treatment options in line with client payment options. Again, she or he may, potentially, offer euthanasia, at least in some countries including Denmark, UK and the U.S., or reject the client and animal (in less severe cases where the veterinarian is under no legal obligation to take the case on). The hypothesis of this study is that financially limited clients present ethical challenges to veterinary practices, and that decisions on how to handle such problems are typically contextual and depend on factors relating to the animal, the type and severity of the situation, and the characteristics of the client, the veterinarian and the clinic. These contextual factors are expected to be wide-ranging, and to include the veterinarian-client relationship, and the veterinarian's level of animal advocacy and her or his past experience of the client-animal bond. Martin and Taunton (2006) have shown that veterinarians actively evaluate the degree of bonding between clients and their animals, and that the evaluation affects the way veterinarians practice medicine. The type and severity of the animal's condition can also be expected to have 
an impact on decision-making, as well as the social and financial status of the client, and the practice's finances and its implementation (or not) of a management policy. Following Batchelor and McKeegan (2012), the veterinarian's gender is also expected to be an influential factor in treatment decisions.

The present study was undertaken in Denmark and makes use of a questionnaire survey sent to all Danish small animal practices. The objective was to answer the following four questions: 1) How frequently do veterinarians encounter financially limited clients? 2) What are common practices when handling financially limited clients? 3) What contextual factors affect veterinary treatment decisions, and how do they do so? 4) How do past exposure to financially limited clients, and demographic and practice-specific factors, affect treatment decisions?

The results of the study should be of interest outside Denmark. In Denmark small animal veterinary practice is a profession that provides services for which clients have to pay out of their own pocket, as it is in most other Western countries. In some countries veterinarians will face dilemmas relating to clients that are not able to pay on a less regular basis due to either high uptake of companion animal health insurance, as in Sweden, or due to a high level of support from charities, as in the UK, but even in these countries dilemmas with financially limited clients are still part of the every day life of small animal veterinarians.

\section{Materials and methods}

Survey recruitment and sample - All small animal practices or mixed practices with a minimum of one small animal veterinarian were contacted. The eligible veterinary practices were selected from a member list held by the Danish Veterinary Association (DDD). Financially responsible veterinarians, owners/co-owners of the practice, and employed veterinary staff were all invited to participate. Only one veterinarian per practice was permitted to fill out the questionnaire, since the main point of the survey was to record the experiences and routines of the practice. In all, 300 practices met the recruitment criteria and received both invitation letters and emails with direct access to the online questionnaire. Email and telephone reminders were issued in the weeks after the survey questionnaire opened for participation in April 2015. In total, 195 persons completed the questionnaire and the dropout rate was 5\% (11/206). This was a $65 \%$ response rate, which is quite satisfactory judging by current response rate levels in Denmark. Furthermore, non-response analysis revealed a very good fit between population census and the sample. Thus the proportion of females $(60.5 \%)$ and males $(39.5 \%)$ in the sample is very similar to the total study population (females 67\%, males $33 \%$ ). The geographical distribution of the sample is also very similar to that of the study population (see Table 1). For this reason, the risk of non-response bias appears to be limited. 
Table 1 - Analysis of existing non-response bias from actual geographic location of practice.

\begin{tabular}{|l|l|l|l|l|}
\hline & \multicolumn{2}{|l|}{$\begin{array}{l}\text { Population } \\
\mathrm{N}=300)\end{array}$} & \multicolumn{2}{l|}{$\begin{array}{l}\text { Sample } \\
(\mathrm{N}=195)\end{array}$} \\
\hline Capital area incl. Bornholm & 93 & $\mathbf{3 1 \%}$ & 59 & $\mathbf{3 0 . 3 \%}$ \\
\hline Zealand & 53 & $\mathbf{1 7 . 7 \%}$ & 36 & $\mathbf{1 8 . 5 \%}$ \\
\hline Lolland, Falster, Møn & 9 & $\mathbf{3 \%}$ & 5 & $\mathbf{2 . 6 \%}$ \\
\hline North Jutland & 28 & $\mathbf{9 . 3 \%}$ & 18 & $\mathbf{9 . 2 \%}$ \\
\hline Middle and South Jutland & 90 & $\mathbf{2 9 . 7 \%}$ & 56 & $\mathbf{2 8 . 7 \%}$ \\
\hline Funen incl. islands & 28 & $\mathbf{9 . 3 \%}$ & 21 & $\mathbf{1 0 . 7 \%}$ \\
\hline
\end{tabular}

Survey design and measures - Qualitative interviews with 12 small animal veterinarians were initially carried out in order to obtain in-depth accounts of veterinarians' common practices when handling financially limited clients, and to gain insight into the contextual factors influencing treatment decisions. The veterinarians selected to participate in the interviews were the financially responsible of their practice and they came from 12 different practices exclusively working with companion animals. The practices were recruited based on a number of demographic criteria, such as geographic location (population size of the city, average yearly net income of the municipality), the size of the practice (number of veterinarians), number of years of experience of the selected veterinarian, as well as their gender (male/female).

The interviews revealed that the veterinarians differed in their approach to situations with financially limited clients, experienced varying levels of impact on a personal level, and were motivated to differing degrees to provide treatment for the animals. Decisions to euthanize animals where clients had financial limitations were found to be a source of particular concern, as well as clients' emotional reactions to situations where finance was limiting treatment options. This information provided valuable input to the development of the questionnaire study and specifically to the case scenarios that were included, in order to model potential real life situations and thereby to achieve a high level of authenticity.

The questionnaire was conducted in Danish and consisted of 24 questions of which 23 were close-ended and one was open-ended. Based on how the participants answered the questionnaire, non-relevant questions were filtered away and the number of questions each participant received therefore varied. The setup of the online questionnaire made it impossible for the respondents to skip specific questions and there are therefore no missing values. In the questionnaire, the respondents were asked to state their gender, years of experience as a veterinarian in a small animal practice, whether they were financially responsible or employees without that responsibility, and the number of times a month they encountered financially limited clients in order to examine how demographic and practice specific factors affect veterinarians' treatment decisions. Common handling practices were explored through questions about whether or not the veterinarians offered different treatment options to financially restricted and unrestricted clients. One question examined whether, and on what terms, pay-by-instalment agreements were offered to new and regular clients. Another question 
was raised to examine if a policy on the management of financially limited clients had been implemented in the practice, and if so whether this policy was a verbally communicated, documented in writing, or one of contacting the financially responsible veterinarian. Where a policy was in place the respondent was asked which of the following four treatment options most closely resemble the practice policy:

1. 'Treatment whatever the cost': I perform the necessary diagnostics and treat regardless of the potential costs. A solution must be found, e.g. in terms of an instalment agreement.

2. 'Treatment realistic, potential euthanasia': I perform the initial necessary diagnostics but the following treatment is based on what is realistic for the client to pay/pay off. If I estimate that the client is not likely to pay/pay off a sufficient amount of the cost, I will offer euthanasia.

3. 'Treatment offering euthanasia': I offer to euthanize the animal.

4. 'Rejection': I reject the client and animal.

To assess the extent to which contextual factors influence treatment options, six case scenarios were constructed. These described situations with animals with different diagnoses varying in type and severity, and with different types of client and client relations. Four of the case scenarios involved animals with different conditions, prognoses, degrees of severity, and associated treatments needed, and differing costs - all designed to investigate the importance of the type and severity of the animal condition. These were:

- 'Cat hit by car': A client enters the clinic with a seven-year-old cat that has been hit by a car. The client tells you that he cannot pay for the treatment now. The cat shows clear signs of pain; it vocalises and does not move.

- 'Dog with fracture': A client enters the clinic with a five-year-old dog and explains that it suddenly started limping after jumping down from a raised platform. The client tells you that she cannot pay for the treatment now. The dog does not bear weight on the right front leg and shows clear signs of pain. You suspect a fracture of radius and/or ulna.

- 'Dog potentially having fleas': A client enters the clinic with her dog and says that it keeps scratching itself. The client suspects that the dog has fleas but states that she cannot pay for the treatment now.

- 'Dog with dystocia': A client enters the clinic with her/his dog that has acute dystocia. The waters have broken but the labour has not started yet. You suspect that a puppy is blocking the birth canal. If the bitch and her puppies are to have a chance of survival you think that a caesarean section is required. The client tells you that he cannot pay for a caesarean section now.

To study the importance of clients' expressed emotions an additional case scenario was devised: 
- 'Mrs Larsen - dog with otitis': Mrs Larsen enters the clinic with her dog Molly and explains that Molly sometimes seems irritated and scratches her ears. Mrs Larsen asks you to examine Molly but says that she cannot pay now. You explain to Mrs Larsen that she has to pay today if Molly is to be examined, which causes Mrs Larsen to break down in tears.

Finally, a case scenario was created to investigate whether a certain client group was perceived as vulnerable, and whether this perception inclined the veterinarians to disregard financial considerations and provide medical care:

- 'Homeless person - dog with pyometra': A homeless person enters the clinic with his dog Rita. Rita has become increasingly depressed and urinates more than usual. It turns out that she has pyometra and you estimate that an operation is necessary. The homeless person tells you that he cannot pay now.

For each of the six case scenarios respondents were asked to choose which treatment (if any) they would offer the client. Response options were similar to the four summaries (1)-(4) set out above regarding practice policies. For the six scenarios all respondents were prompted for their specific treatment choice. The scenarios 'Cat hit by car', 'Dog with fracture', and 'Dog with dystocia' describe cases with injured and critically ill animals that veterinarians in Denmark are legally permitted to treat. The veterinarian's decision of the treatment provided may therefore be impacted by legal requirements. The case scenario 'Homeless person $-\mathrm{dog}$ with pyometra' can be viewed as a borderline case. It may be argued that, according to Danish law, treatment is legally required while it may also be disputed that this is the case. In the scenario 'Dog potentially having fleas' a suggestion that clients at their own expense could use a flea control product was added to choice option (4) 'Rejection'. All of the animals in the case scenarios were either described as being neither young nor old, or given no age at all, and the financially limited clients were all portrayed as people not formerly known to the veterinarian.

The survey questionnaire was pre-tested with five randomly selected veterinarians before being distributed to ensure that it could be correctly understood and was in other ways valid. The online survey questionnaire was designed and administrated using a survey program (SurveyXact, Rambøll Management). The questionnaire is available upon request to the corresponding author.

Data analysis - To analyse the findings of the questionnaire, univariate descriptive statistics were displayed either in tables, figures, or text. Spearman's Rho directional test of associations (suitable for ordinal level variables) was employed in all bi-variate analyses. Composite variables were computed from the six case scenarios by calculating the number of times each of the four response options was chosen per respondent. This created the following four measures: propensity to offer (1) 'Treatment whatever the cost' (sample range 0-6), (2) 'Treatment realistic, potential euthanasia' (sample range 0-6), (3) 'Treatment offering 
euthanasia' (sample range 0-3), and (4) 'Rejection' (sample range 0-3). As these four propensity measures were composite scales calculated on basis of the six scenarios, the theoretical range for each of them were 0-6.The measures of 'Treatment offering euthanasia' and 'Rejection' had a sample range of $0-3$ because these options were chosen less frequently by the respondents.

In order to identify practice specific and demographic factors that may explain differential treatment, four Poisson regression analyses were carried out, one for each propensity variable. Poisson regression was employed since the dependent measures are count variables. The explanatory variables inserted in the regression analyses as indicators of the influence from demographic factors on choice of treatment options were: size of the veterinary practice (number of veterinarians in the practice: $1=1$ veterinarian, $2=2-4$ veterinarians, $3=5$ or more veterinarians), ownership status (whether the respondent owns the practice $=1$, or not $=0$ ), work experience (the number of years of experience as a practicing veterinarian: $1=1-10$ years, $2=11$ 30 years, $3=31$ years or more), and gender. The explanatory variables inserted in the regression analyses as indicators of the influence from practice specific factors on choice of treatment options were: frequency of encounters with financially limited clients, type of management policies on financially limited clients $(1=$ none, $2=$ verbally communicated, $3=$ written or to contact the financially responsible person), and whether the respondent reported to have become more dismissive (based on response to the question: "Have experiences during your veterinarian career changed the way you react to clients that cannot pay?": 1=more dismissive, $0=$ not more dismissive). In all analyses p-values $<0,05$ were considered significant. All analyses were carried out in IBM SPSS Statistics version 21. Poisson regression analyses were conducted using the GENLIN program in SPSS. The measures used in this study have not been subjected to psychometric evaluation. The results presented here should therefore be interpreted with this limitation in mind.

\section{Results}

Demographic and practice characteristics $-84.1 \%$ of the responding veterinarians were responsible for practice finances and $15.9 \%$ were employees at the practice with no such responsibility. The respondents had variable levels of experience as veterinarians in a small animal practice, ranging from $1-40+$ years, and their clinics varied in size from 1 or 2 employees to 11 or more.

\section{Frequency of encounters with financially limited clients, and impacts on treatment offered} and payment options - Only $8.2 \%$ of respondents reported that they never (or less than once per month) had experiences with clients coming to the practice and expressing an inability to pay for the necessary service or product. The remaining respondents experienced this on a regular basis. 33.8\% reported 3-4 incidents per month, $24.6 \%$ reported 5-10, 19.5\% reported 12 and $13 \%$ reported more than 10 . There was a positive association between frequency of encounter with financially limited clients and agreement with the option "I have become more dismissive" when faced with the question "Have experiences during your veterinarian career changed the way you react to clients that cannot pay?" (Spearman's Rho 0.163; p-value $=0.02$ ). 
The study also showed a positive association between frequency of encounters and requiring new clients to pay a percentage of the bill on the day of treatment (Spearman's Rho 0.203; pvalue $<0.00)$.

Treatments offered to paying and financially limited clients - A majority of respondents (79\%) said that different treatments were offered to financially limited, as opposed to regular paying clients. The remainder $(21 \%)$ denied this. Of the $79 \%, 48.2 \%$ responded that financially limited clients would primarily be offered treatment options when an animal's situation is critical, which kept costs at a level the client could realistically be expected to pay off. If an operation could cure the animal, the financially limited client would be offered the same treatment option as the client with funds. Of the 79\%, 30.8\% responded that financially limited clients would only be offered treatment options that helped when an animal's situation was critical and kept costs at a level the client could realistically pay. This may include euthanasia.

Pay-by-instalment agreements with new clients $-42.6 \%$ of the responding veterinarians required a certain percentage of the bill to be paid on the same day when offering instalment agreements to new clients; $40 \%$ did not offer instalment agreements to new clients; $12.3 \%$ replied that both new and regular clients were offered instalment agreements on the same terms provided that they had no unpaid bills; and $5.1 \%$ did not offer instalment agreements at all.

Policies on the management of financially limited clients - In total $90.8 \%$ of respondents reported that a verbally communicated policy (43.6\%), or a policy of contacting the person in the practice who is responsible for financial matters $(38.5 \%)$, or a written policy $(8.7 \%)$ had been implemented in the practice; and $9.2 \%$ had no policy implemented. Of that $90.8 \%$ total, $85.3 \%$ stated that the policy was described by treatment option (2) 'Treatment realistic, potential euthanasia'. The remaining treatment options were divided as follows: (1) 'Treatment whatever the cost' (9\%), (3) 'Treatment offering euthanasia' (4.5\%), and (4) 'Rejection' $(1.1 \%)$.

Treatment offered to financially limited clients - Results from the six case scenarios showed significant differences in treatment options for financially limited clients, depending on the specific case (Figure 1). The treatment option (1) 'Treatment whatever the cost' was chosen by the majority of the respondents for the two case scenarios 'Dog with dystocia' and 'Mrs Larsen - dog otitis'. Option (2) 'Treatment realistic, potential euthanasia' was chosen by the majority of respondents for the four case scenarios 'Homeless person - dog with pyometra', 'Dog with fracture', 'Dog potentially having fleas', and 'Cat hit by car'. Taking all six of the scenarios together, the most frequently chosen treatment option was (2) 'Treatment realistic, potential euthanasia' (avg. score 3.13), followed by (1) 'Treatment whatever the cost' (avg. score 1.96), (4) 'Rejection”' (avg. score 0.56), and (3) 'Treatment offering euthanasia' (avg. score 0.34$)$. 
Figure 1 - Distribution of treatment options offered to financially limited clients in the six case scenarios.

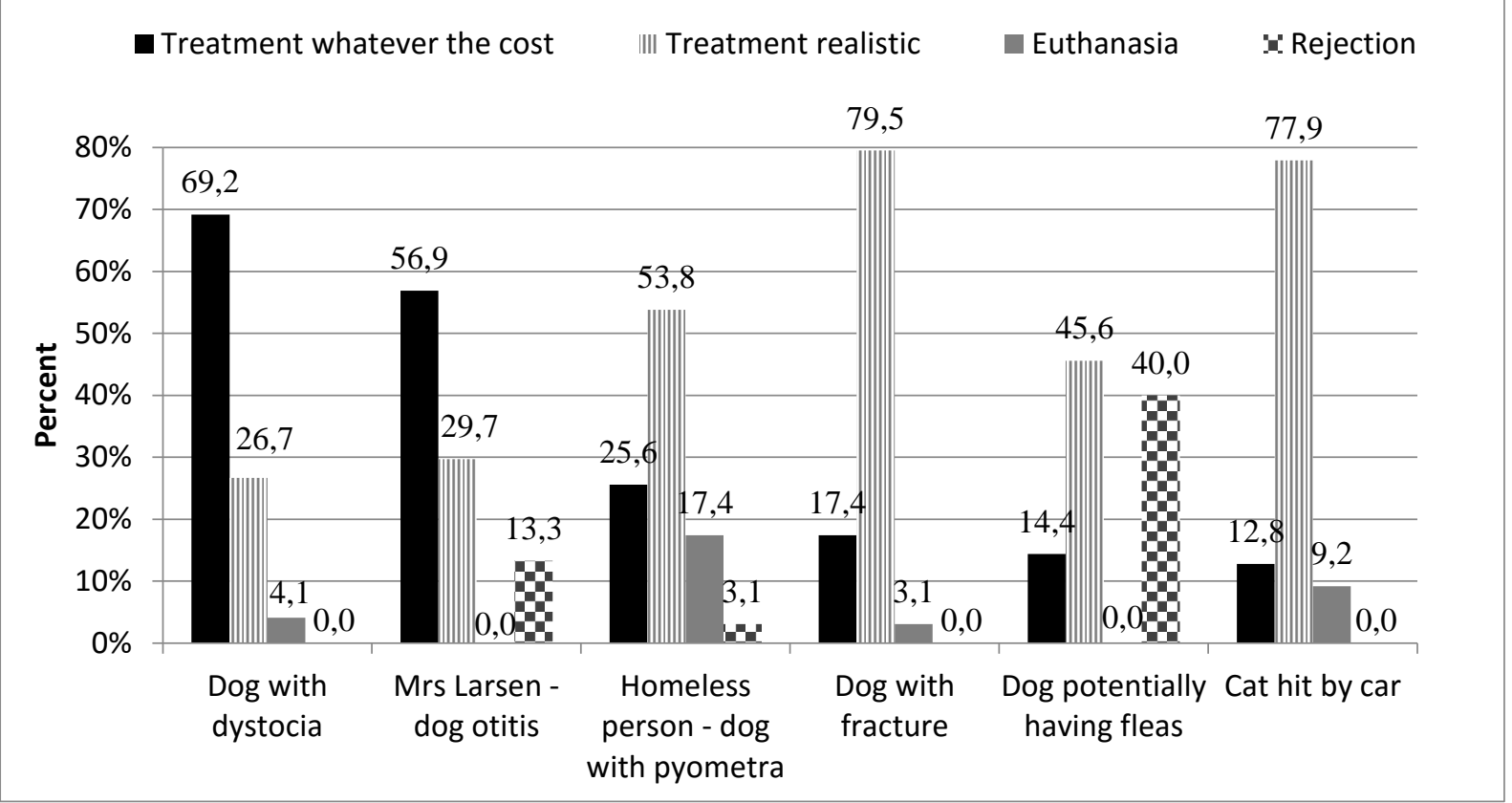

\section{Demographic and practice-specific factors}

The results from the four Poisson regression analyses indicate that some practice specific and demographic factors seem to have an effect on the treatment provided in the six case scenarios (Table 2). The most important factor for the veterinarians' treatment propensity is whether they report having become more dismissive towards clients that cannot pay as the result of experiences during their veterinary career. Those that have become more dismissive were significantly less inclined to endorse (1) 'Treatment whatever the cost'; they were significantly more inclined to opt for (2) 'Treatment realistic, potential euthanasia', and (3) 'Treatment offering euthanasia', and to opt for (4) 'Rejection'. In addition, gender affected the propensity of the veterinarian to endorse (1) 'Treatment whatever the cost', with women being more inclined to choose this option. Frequency of encounters with financially limited clients also affected two of the treatment propensities: increasing numbers of monthly encounters with clients struggling to pay decreased the veterinarian's propensity to endorse (3) 'Treatment offering euthanasia' and (4) 'Rejection'. 
Table 2 - Effect from demographic and practice-specific factors on four types of treatment propensities $(\mathrm{N}=195)$

\begin{tabular}{|c|c|c|c|c|c|c|c|c|c|c|c|c|c|c|c|c|}
\hline & \multicolumn{4}{|c|}{ Treatment whatever the cost } & \multicolumn{4}{|c|}{$\begin{array}{l}\text { Treatment realistic, } \\
\text { potential euthanasia }\end{array}$} & \multicolumn{4}{|c|}{$\begin{array}{l}\text { Treatment } \\
\text { euthanasia }\end{array}$} & \multicolumn{4}{|c|}{ Rejection } \\
\hline & B & s.e. & Wald & sig. & B & s.e. & Wald & sig. & $\mathrm{B}$ & s.e. & Wald & sig. & $\mathrm{B}$ & s.e. & Wald & sig. \\
\hline (Intercept) & 0.275 & 0.2919 & 0.891 & 0.345 & 1.221 & 0.2280 & 28.672 & 0.000 & -0.556 & 0.7308 & 0.579 & 0.447 & -0.924 & 0.5763 & 2.568 & 0.109 \\
\hline $\begin{array}{l}\text { Gender (ref: man) } \\
\text { Woman }\end{array}$ & 0.292 & 0.1124 & 6.748 & 0.009 & -0.124 & 0.0862 & 2.068 & 0.150 & -0.429 & 0.2570 & 2.782 & 0.095 & 0.003 & 0.2037 & 0.000 & 0.990 \\
\hline $\begin{array}{l}\text { Ownership (ref.: no) } \\
\text { Yes }\end{array}$ & 0.205 & 0.1737 & 1.389 & 0.239 & -0.111 & 0.1269 & 0.767 & 0.381 & 0.071 & 0.4624 & 0.023 & 0.878 & 0.071 & 0.3241 & 0.048 & 0.826 \\
\hline Years of experience as veterinarian & 0.157 & 0.0928 & 2.871 & 0.090 & -0.100 & 0.0765 & 1.703 & 0.192 & 0.048 & 0.2225 & 0.047 & 0.828 & -0.002 & 0.1793 & 0.000 & 0.990 \\
\hline Number of veterinarians & -0.050 & 0.0774 & 0.411 & 0.522 & 0.041 & 0.0587 & 0.482 & 0.488 & -0.300 & 0.1971 & 2.310 & 0.129 & 0.023 & 0.1381 & 0.027 & 0.868 \\
\hline Frequency of encounters & 0.060 & 0.0322 & 3.437 & 0.064 & 0.015 & 0.0260 & 0.314 & 0.575 & -0.215 & 0.0821 & 6.865 & 0.009 & -0.156 & 0.0609 & 6.539 & 0.011 \\
\hline $\begin{array}{l}\text { Management policy (ref: yes, verbally } \\
\text { communicated) } \\
\text { None } \\
\text { Yes, written or asked financial responsible }\end{array}$ & $\begin{array}{l}-0.066 \\
-0.075\end{array}$ & $\begin{array}{l}0.1772 \\
0.1111\end{array}$ & $\begin{array}{l}0.137 \\
0.451\end{array}$ & $\begin{array}{l}0.711 \\
0.502\end{array}$ & $\begin{array}{l}0.005 \\
0.053\end{array}$ & $\begin{array}{l}0.1579 \\
0.0865\end{array}$ & $\begin{array}{l}0.001 \\
0.373\end{array}$ & $\begin{array}{l}0.974 \\
0.542\end{array}$ & $\begin{array}{r}0.630 \\
-0.300\end{array}$ & $\begin{array}{l}0.3851 \\
0.2731\end{array}$ & $\begin{array}{l}2.679 \\
1.208\end{array}$ & $\begin{array}{l}0.102 \\
0.272\end{array}$ & $\begin{array}{c}-0.192 \\
0.030\end{array}$ & $\begin{array}{l}0.4448 \\
0.2005\end{array}$ & $\begin{array}{l}0.186 \\
0.022\end{array}$ & $\begin{array}{l}0.667 \\
0.882\end{array}$ \\
\hline $\begin{array}{l}\text { More dismissive (ref: no) } \\
\text { Yes }\end{array}$ & -0.686 & 0.1068 & 41.310 & 0.000 & 0.188 & 0.0920 & 4.173 & 0.041 & 1.198 & 0.3288 & 13.282 & 0.000 & 1.136 & 0.2699 & 17.708 & 0.000 \\
\hline
\end{tabular}





\section{Discussion}

Results from the survey show a high prevalence of financially limited clients visiting Danish small animal veterinary clinics. This prevalence is consistent with the results reported by Batchelor and McKeegan (2012), who found financial limitations on treatment to pose the most common dilemma for veterinary surgeons in the UK. Batchelor and McKeegan also showed that dealing with this dilemma was often stressful for veterinarians. Similarly, the results indicate that the ethical issues that arise affect veterinarians personally and guide the selection of the treatment options.

An overall conclusion from the survey is that veterinarians display high willingness to help financially limited clients far beyond what is legally required of them. However, the willingness to help beyond the legally required minimum varies from one veterinarian to another and is dependent on factors relating to the animal, the client and the needs of the practice as a business. Willingness to help was most clearly displayed in the results obtained in connection with the scenario of a dog with dystocia. Here, the vast majority of responding veterinarians chose the option (1) 'Treatment whatever the cost', thus agreeing to provide the necessary treatment and perform a caesarean section with a risk of it being done at the veterinary clinic's expense. The willingness to treat is here much higher than it is in the scenarios 'Cat hit by car' and 'Dog with fracture' even though the animals in all three scenarios are in a situation where euthanasia is the only alternative to therapeutic treatment.

In her doctoral dissertation, Morgan (2009) investigated the way Canadian veterinarians handle ethical dilemmas. She found that the euthanasia of healthy young animals often generates an ethical dilemma for the veterinarian and is often avoided if possible. She also described how veterinarians sometimes donate the necessary service when clients cannot pay for treatment. The findings on the dystocia case are in line with Morgan's. However, it was a surprise to us to discover that the veterinarians' reactions to the dystocia case differed significantly from those they had to the other scenarios where treatment was possible and was the only alternative to euthanasia. Clearly, then, veterinarians are particularly affected by cases involving unborn and young animals, which tend to elicit pro-bono work. The animal's status, as young or unborn, therefore seems to be an essential factor when veterinarians decide on the level of treatment to be offered.

The results from the three case scenarios 'Cat hit by car', 'Dog with fracture', and 'Dog potentially having fleas' show that the severity of the animal's condition, the different needs for treatment, and treatment costs, all to some degree affect the veterinarian's choice of treatment when she or he is dealing with financially limited clients. Lower degrees of severity in the animal condition lead to a high proportion of the responding veterinarians rejecting the client and animal. This emerged from the scenario 'Dog potentially having fleas', where $40 \%$ of respondents chose to reject the client and animal with a suggestion that the client should try a flea control product. Veterinarians in Denmark are not legally obliged to provide treatment for dogs that appear to have fleas, and it could be expected that in this situation the veterinarians 
would be less inclined to help the client and the animal. Interestingly, however, there is no substantial difference in the propensity to endorse (1) 'Treatment whatever the cost' when the flea case is compared with 'Dog with fracture' and 'Cat hit by car'. The low treatment expense in the flea case could be one reason for the propensity to provide treatment 'whatever the costs' here. Another reason may be that if the fleas are not properly treated the animal can develop flea allergy dermatitis, which is a very painful condition.

It was not expected that 'Dog potentially having fleas' would be linked with the option of euthanasia, and this seemed to be correct: none of the respondents offered euthanasia as the only treatment option here. The case scenario 'Cat hit by car' was associated with a greater tendency to offer euthanasia as the only treatment than 'Dog with fracture'. To some extent this may reflect uncertainty about the severity of the injuries to the cat and a guarded prognosis, the thought being that it is best to potentially prevent the cat having to go through numerous operations, stress and suffering at high cost to the practice. Species differences may be significant also, as studies have shown a tendency for veterinary clients to be more inclined to spend resources on dogs than on cats (Burns 2013; American Pet Products Association 2015), to be more likely to arrange veterinary care for dogs than they are for cats (Lue and others 2008; Volk and others 2011), and to obtain health insurance for dogs rather than for cats (Agria 2015). It is likely that these differences in dog and cat care have an impact on veterinarians' choice of treatment, but since this study only included one scenario with the cat as an example, further research on this topic is required.

In addition to the various factors associated with the animal's condition, the relationship between the veterinarian and client was also expected to be a very important parameter in determining treatments offered to financially limited clients. Over recent years, the body of research findings on the veterinarian-client relationship has grown, and it has been asserted that "relationship-centred care" is important in the practice of veterinary medicine (Shaw and others 2004; Frankel 2006). Relationship-centred care represents a joint venture between the veterinarian and client to provide optimal care for the animal, and it therefore emphasizes the role of a genuine interest in the clients' personal and financial circumstances.

In the results from this study, relationship-centred care can be detected as clients' emotional reactions clearly affect the veterinarians, encouraging them to endorse (1) 'Treatment whatever the cost'. This is evident when comparing the veterinarians' responses in two case scenarios: 'Mrs Larsen - dog otitis' and 'Dog potentially having fleas'. Both cases represent animal conditions of rather low severity, but there is a difference in client reaction. Mrs Larsen becomes emotionally upset and this is probably what prompts the veterinarians to be significantly more inclined to endorse (1) 'Treatment whatever the cost' and significantly less inclined to reject the client and animal.

Thus client emotion seems to make the veterinarians less focused on profit and more interested in helping the client. Besides a general compassionate interest in other human beings and the already mentioned relationship-centred care approach, another reason for this priority may be 
that clients' expressions of emotion are an indication of a strong attachment to their animals. The client-animal relation is also a focal area in the relationship-centred approach, and as mentioned in the introduction, clients' affectionate relationships with their animals do have an impact on veterinarians during consultations. Nor can it be disregarded that some of the responding veterinarians assumed that Mrs Larsen was a senior citizen and hence a somewhat vulnerable client, because in Denmark it is a rather formal practice to address people by their last name, and it is primarily aimed at elderly people. This interpretation may also have increased their willingness to help.

In the survey veterinarians' ways of handling another disadvantaged group, namely homeless people were examined. The results from the case scenario 'Homeless person - dog with pyometra' reveal no significant association between this client group and endorsement of (1) 'Treatment whatever the cost'. Most of the responding veterinarians opted for (2) 'Treatment realistic, potential euthanasia' in this case scenario, thus demonstrating some degree of charity and willingness to help. None of the responding veterinarians rejected the client in any of the other critical case scenarios, but in the case with the homeless person, a few veterinarians (3.1\%) chose this option. It can be discussed if this violates Danish legislation, which requires veterinarians to provide the necessary first aid to seriously injured animals or animals with painful diseases or dystocia. The responding veterinarians were also more likely to offer euthanasia as the only option here than they were in the other scenarios. Although it can be difficult for the veterinarian to judge an individual's social and economic status solely by her or his appearance, reasons for the higher propensity to reject and offer euthanasia might include the fact that homeless people are exposed to a variety of prejudices, and that veterinarians might have concerns about the welfare of the animals that homeless people keep. The veterinarians may also believe that there is substantial risk that they will never receive payment if they choose to provide the necessary treatment.

Although situations involving dystocia and emotional reactions from clients were found to reduce the difference between treatments offered to financially limited clients and those offered to regular paying clients, the vast majority of respondents $(79 \%)$ indicated that they generally offer somewhat different treatment options to clients with limited means and clients who can pay. One reason for this may be that if clients with payment problems are offered the same treatment options as those for regular paying clients, it can be discomforting for the client or even a source of humiliation. Additionally, veterinarians may not want to further indebt the client. Thus the Danish veterinarians seem to display a certain amount of paternalism in directing client choices (Morgan 2009).

Results from the case scenarios indicate that respondents tend to keep costs at a realistic level for the client, and this also supports the idea that many Danish veterinarians adopt a paternalistic approach. On the other hand, some veterinarians may decline to offer treatments to financially limited clients that they would offer to regular paying clients because they are aware they have a responsibility to ensure the practice is financially healthy, or because they are obliged to operate within a strict management policy. Furthermore, financially limited clients are not 
offered instalment agreement on equal terms, and this seems to be connected with assumptions about their allegiance to the veterinarian or practice in question. This is evident from the results, which indicate that $42.6 \%$ of responding veterinarians required a certain percentage of the bill on the same day when offering instalments agreements to new clients, and that $40 \%$ did not offer instalment agreements to new clients at all. It is a good question whether some scenarios (e.g. those involving dystocia and the clients' emotional reactions), which have been shown to increase the veterinarians' willingness to help in this study, would represent exceptions to this tendency.

A small proportion of the respondents $(21 \%)$ indicated that they generally offer the same treatment options to financially limited clients and regular paying clients. Offering the same treatment to everyone, which seems to be promoted in other countries, e.g. UK, indicates that the veterinarians give priority to a concern that the clients are given autonomy to make informed decisions. Concern for clients' autonomy is emphasized in countries such as Canada, the U.S., and UK, by codes of conduct, or guidelines, designed to ensure that information about reasonable and essential treatment options and their associated fees are made available to the client (Flemming and Scott 2004; British Columbia Veterinary Medical Association 2009; Royal College of Veterinary Surgeons n.d.). In this respect, Klingborg and Klingborg (2007) have suggested that discussing clinical alternatives and their associated fees with the client demonstrates a level of caring for both animal and client.

Written practice policies on how to handle financially limited clients were found to be very rare. The vast majority of responding veterinarians referred either to a verbally communicated policy or to a policy of contacting those handling finance. Plainly, these procedures involve fairly weak guidelines, as only a written document can be the basis of a genuine management policy. However, only a minority of the veterinarians $(8.7 \%)$ had implemented a written policy. This could reflect the fact that the majority of the responding veterinarians were owners - some, the only veterinarian in the practice - that rather obviates the need for a written policy. Nevertheless, the general impression from this survey is that the handling of financially limited clients proceeds situation by situation. This could explain the varying responses to the case scenarios and why a large proportion of veterinarians adhered to a guideline/policy of providing (2) 'Treatment realistic, potential euthanasia'. This treatment option permits a high degree of interpretation and autonomy, and this means that it is difficult to use it to direct or protect the employee when she or he is dealing with potential moral dilemmas caused by clients' financial limitations. The difficulty of agreeing and operating a codified management policy on how to handle financially limited clients may pose a challenge in future, given that the tendency in small animal veterinary practice is towards larger corporate practices. These practices, on the one hand, seem to require codified practices as a management tool, but on the other hand, they may encounter reputational issues and problems with the work satisfaction of veterinarians and other staff if, as a matter of policy, they refuse to help clients who are unable to pay.

Relatedly, Kogan and others (2015) have emphasized that the types of pro bono work most often seen in veterinary medicine reflect an $a d$ hoc, individual approach as opposed to an 
organized, systematic approach, and that this typically entails that private practitioners provide pro bono services of their own accord out of fellow feeling or a sense of duty. A management policy is supposed to save the individual veterinarian from having to be the judge of which client or animal ought to receive reduced fees or instalment agreements (Tannenbaum 1995). However, a policy dictated from above may conflict with the individual veterinarian's moral values and beliefs, and also diminish her or his ability to respond to individual circumstances and contextual factors, which ability is arguably an essential part of the veterinarians' daily practice. Although the opposite is obviously intended, management policies may further add to the complexity of decision-making and leave veterinarians feeling even more frustrated.

In this study it was examined how exposure to financially limited clients, management practices, and demographic and practice-specific factors affects veterinarians' decisions on treatments to be offered to clients with limited ability to pay. The results show that in the case scenarios female veterinarians were more inclined than their male colleagues to endorse (1) 'Treatment whatever the cost'. Bearing in mind the findings made by Batchelor and McKeegan (2012), it was also expected that female veterinarians were more morally engaged on behalf of the patients and the clients. A strong propensity to offer treatment to financially limited clients regardless of the cost involved indicates emotional engagement and a high degree of willingness to help the client find treatment solutions other than euthanasia; and this supports our expectation. Fogle and Abrahamson (1990) also found that female veterinarians were more emotionally affected by a decision to carry out euthanasia than male veterinarians, and Williams and others (2005) found that female veterinarians score pain in dogs and cats higher that their male colleagues. Therefore, it seems likely that more female veterinarians may seek to provide effective therapeutic treatment and avoid euthanasia by adopting a personal policy of treating whatever the cost.

The number of years of experience as a veterinarian did not seem to be an important factor in veterinarians' decisions about the handling of financially limited clients. In their study of veterinarians' stress ratings, Batchelor and McKeegan (2012) also concluded that years of experience had no impact. What seemed to be significant in the survey was the veterinarians' own assessments of whether they had become more dismissive as their careers progressed. Respondents who agreed with the statement that experiences during their veterinary career have made them more dismissive of financially limited clients showed a lower propensity to endorse (1) 'Treatment whatever the cost' in the case scenarios, and they also had a higher frequency of encounters with financially limited clients. The correlation between a high frequency of encounters with financially limited clients and self-reported dismissiveness could indicate that several years of experience come with a higher probability that the veterinarian will have a large number of encounters of the relevant kind. But as mentioned, years of experience, as an individual variable, was not found to be significant in veterinarians' treatment decisions for financially limited clients. Years of experience can, however, play an influential role in treatment decisions relating to such clients because a lengthy career running over many years could involve a variety of incidents of the sort that lead to a more dismissive attitude. On the other hand, influential incidents that could increase the likelihood of a more dismissive attitude 
towards financially limited clients can also happen over a short period of time, of course, and do not necessarily depend on several years of experience.

The initial hypothesis of this study was that financially limited clients present ethical challenges to small animal veterinarians, and that decisions about how to handle the problems that arise are typically contextual and depends on factors relating to the animal, the client and the veterinarian. The results of this study met our expectations and showed that, in general, small animal veterinarians experience situations with financially limited clients on a frequent basis, and that they often provide treatments other than euthanasia without any guarantee of payment. The basis of the veterinarians' decisions has been shown to be highly context-sensitive and situations involving emotional clients and unborn animals stand out as being particularly morally loaded. Furthermore, the very high response rate in this study suggests that the issue of how to handle financially limited clients is close to the heart of most veterinarians working in small animal practice.

The main limitation of this study is that it was only undertaken in one country which may differ in a number of relevant respects from other countries of interest, e.g. regarding income, social inequality and other demographic factors concerning the client population, in the availability of charities supporting financially limited clients, and regarding legal requirements and professional norms relating to the veterinary profession. Future research should, in light of this, either focus on cross-country studies or on studies conducted in one country in a way that allows for comparisons with the present study.

\section{Acknowledgments}

The authors want to thank the veterinarians who were interviewed and those who answered the survey questionnaire. The authors also thank the Department of Food and Resource Economics for financial support and Paul Robinson and Clare Palmer for language editing.

\section{References}

Agria (2015) Ny undersøgelse: Flere hunde og katte får sygeforsikring. www.agria.dk/pressecenter/pressemeddelelser-2015/ny-undersogelse-flere-hunde-og-kattefar-sygeforsikring/. Accessed January 25, 2016

American Pet Products Association (2015) 2015-2016 APPA National Pet Owners Survey. Greenwich. American Pet Products Association

Bachynsky, E. A., Dale, V. H. M., Kinnison, T., Gazzard, J., \& Baillie, S. (2013) A survey of the opinions of recent veterinary graduates and employers regarding early career business skills. Veterinary Record 172, 604-604

Batchelor, C. E. M., \& McKeegan, D. E. F. (2012) Survey of the frequency and perceived stressfulness of ethical dilemmas encountered in UK veterinary practice. Veterinary Record, 170 
British Columbia Veterinary Medical Association (2009) Code of ethics. Bylaws - Appendix A. British Columbia Veterinary Medical Association

Brown, J. P., \& Silverman, J. D. (1999) The current and future market for veterinarians and veterinary medical services in the United States. Journal of American Veterinary Medical Association 215, 161-183

Burns K. (2013) Vital statistic. www.avma.org/news/javmanews/pages/130201a.aspx. Accessed January 25, 2016

Coe, J. B., Adams, C. L., \& Bonnett, B. N. (2007) A focus group study of veterinarians' and pet owners' perceptions of the monetary aspects of veterinary care. Journal of the American Veterinary Medical Association 231, 1510-1518

Coe, J. B., Adams, C. L., \& Bonnett, B. N. (2008) A focus group study of veterinarians' and pet owners' perceptions of veterinarian-client communication in companion animal practice. Journal of the American Veterinary Medical Association 233, 1072-1080

Coe, J. B., Adams, C. L., \& Bonnett, B. N. (2009) Prevalence and nature of cost discussions during clinical appointments in companion animal practice. Journal of the American Veterinary Medical Association 234, 1418-1424

Creswell, J. W. (2003) Research design: Qualitative, quantitative, and mixed methods approaches (2nd ed.). Sage publications

Cron, W. L., Slocum Jr, J. V., Goodnight, D. B., \& Volk, J. O. (2000) Executive summary of the brakke management and behavior study. Journal of the American Veterinary Medical Association 217, 332-338

Flemming, D. D., \& Scott, J. F. (2004) Informed consent doctrine: What veterinarians should tell their clients. Journal of the American Veterinary Medical Association 224, 1436-1439

Fogle B., \& Abrahamson D. (1990) Pet loss: A survey of the attitudes and feelings of practicing veterinarians. Anthrozoos 3, 143-150.

Frankel, R. M. (2006) Pets, vets, and frets: What relationship-centered care research has to offer veterinary medicine. Journal of Veterinary Medical Education 33, 20-27

Gilling, M. L., \& Parkinson, T. J. (2009) The transition from veterinary student to practitioner: A make or break period. Journal of Veterinary Medical Education 36, 209-215

Graaf, G. d. (2005) Veterinarians' discourses on animals and clients. Journal of Agricultural and Environmental Ethics 18, 557-578

Greenebaum, J. (2004) It's a dog's life: Elevating status from pet to "fur baby" at yappy hour. Society \& Animals 12, 117-135

Henry, C., \& Treanor, L. (2012) Exploring entrepreneurship education within veterinary medicine: Can it be taught? Journal of Small Business and Enterprise Development 19, 484499 
Hens, K. (2008) Ethical responsibilities towards dogs: An inquiry into the dog-human relationship. Journal of Agricultural and Environmental Ethics 22, 3-14

Hsieh, H. -F., \& Shannon, S. E. (2005) Three approaches to qualitative content analysis. Qualitative Health Research 15, 1277-1288

Klingborg, D. J., \& Klingborg, J. (2007) Talking with veterinary clients about money. Veterinary Clinics: Small Animal Practice 37, 79-93

Kogan, L. R., McConnell, S. L., \& Schoenfeld-Tacher, R. (2005) Response of a veterinary college to career development needs identified in the KPMG LLP study and the executive summary of the brakke study: A combined MBA/DVM program, business certificate program, and curricular modifications. Journal of the American Veterinary Medical Association 226, 1070-1076

Kogan, L. R., Stewart, S. M., Dowers, K. L., Schoenfeld-Tacher, R., \& Hellyer, P. W. (2015) Practices and beliefs of private practitioners surrounding discounted veterinary services and products. Open Veterinary Science Journal 9, 1-9

Lue, T. W., Pantenburg, D. P., \& Crawford, P. M. (2008) Impact of the owner-pet and clientveterinarian bond on the care that pets receive. Journal of the American Veterinary Medical Association 232, 531-540

Martin, F., \& Taunton, A. (2006) Perceived importance and integration of the human-animal bond in private veterinary practice. Journal of the American Veterinary Medical Association $228,522-527$

Milani, M. (2003) Practical bond considerations: Acknowledging clients' financial limits. Canadian Veterinary Journal 44, 996-999.

Morgan, C. A., \& McDonald, M. (2007) Ethical dilemmas in veterinary medicine. Veterinary Clinics of North America: Small Animal Practice 37, 165-179

Morgan, C. A. (2009) Stepping Up to the Plate: Animal Welfare, Veterinarians, and Ethical Conflicts. Doctoral thesis. University of British Columbia. Vancouver

Power, E. (2008) Furry families: Making a human-dog family through home. Social \& Cultural Geography 9, 535-555

Retsinformation (2004) Lov om dyrlæger. www.retsinformation.dk/Forms/R0710.aspx?id=8024\#K3. Accessed January 25, 2016

Routly, J. E., Taylor, I. R., Turner, R., McKernan, E. J., \& Dobson, H. (2002) Support needs of veterinary surgeons during the first few years of practice: Perceptions of recent graduates and senior partners. Veterinary Record 150, 167-171

Royal College of Veterinary Surgeons n.d. Code of Professional Conduct for Veterinary Surgeons. www.rcvs.org.uk/advice-and-guidance/code-of-professional-conduct-forveterinary-surgeons. Accessed January 25, 2016 
Shaw, J. R., Adams, C. L., \& Bonnett, B. N. (2004) What can veterinarians learn from studies of physician-patient communication about veterinarian-client-patient communication? Journal of the American Veterinary Medical Association, Veterinary Medicine Today: Reference Point 233, 676-684

Tannenbaum, J. (1993) Veterinary medical ethics: A focus of conflicting interests. Journal of Social Issues 49, 143-156

Tannenbaum, J. (1995) Veterinary ethics: Animal welfare, client relations, competition and collegiality (2. ed.). Mosby

Volk, J. O., Felsted, K. E., Cummings, R. F., Slocum, J. W., Cron, W. L., Ryan, K. G., \& Moosbrugger, M. C. (2005) Executive summary of the avma-pfizer business practices study. Journal of the American Veterinary Medical Association 226, 212-218

Volk, J. O., Felsted, K. E., Thomas, J. G., \& Siren, C. W. (2011) Executive summary of the bayer veterinary care usage study. Journal of the American Veterinary Medical Association $238,1275-1282$

Walsh, D. A., Osburn, B. I., \& Schumacher, R. L. (2002) Defining the attributes expected of graduating veterinary medical students, part 2: External evaluation and outcomes assessment. Journal of Veterinary Medical Education 29, 36-42

Williams, V. M., Lascelles, B. D. X., \& Robson, M. C. (2005) Current attitudes to, and use of, peri-operative analgesia in dogs and cats by veterinarians in New Zealand. New Zealand Veterinary Journal 53, 1 